\title{
Canadian Perspectives on the Clinical Actionability of Neuroimaging in Disorders of Consciousness
}

\author{
Grace Lee, Adrian C. Byram, Adrian M. Owen, Urs Ribary, A. Jon Stoessl, \\ Andrea Townson, Christine Stables, Judy Illes
}

\begin{abstract}
Background: Acquired brain injury is a critical public health and socioeconomic problem in Canada, leaving many patients in vegetative, minimally conscious, or locked-in states, unresponsive and unable to communicate. Recent advances in neuroimaging research have demonstrated residual consciousness in a few exemplary patients with acquired brain injury, suggesting potential misdiagnosis and changes in prognosis. Such progress, in parallel with research using multimodal brain imaging technologies in recent years, has promising implications for clinical translation, notwithstanding the many challenges that impact health care and policy development. This study explored the perspectives of Canadian professionals with expertise either in neuroimaging research, disorders of consciousness, or both, on the potential clinical applications and implications of imaging technology. Methods: Twenty-two professionals from designated communities of neuroimaging researchers, ethicists, lawyers, and practitioners participated in semistructured interviews. Data were analyzed for emergent themes. Results: The five most dominant themes were: (1) validation and calibration of the methods; (2) informed consent; (3) burdens on the health care system; (4) implications for the Canadian health care system; and (5) possibilities for improved prognosis. Conclusions: Movement of neuroimaging from research into clinical care for acquired brain injury will require careful consideration of legal and ethical issues alongside research reliability, responsible distribution of health care resources, and the interaction of technological capabilities with patient outcome.
\end{abstract}

RÉSUMÉ: Perspectives canadiennes à propos de l' « actionnabilité » clinique de la neuroimagerie dans les troubles de la conscience. Contexte: Une lésion cérébrale acquise est un problème de santé publique et un problème socioéconomique important au Canada et ce type de lésions laisse plusieurs patients dans un état végétatif, de conscience minimale ou de verrouillage avec absence de réponse et incapacité à communiquer. Des progrès récents de la recherche en neuroimagerie ont montré la présence d'un état de conscience résiduel chez quelques patients particuliers ayant subi une lésion cérébrale, ce qui suggère la possibilité qu'un diagnostic erroné ait été posé et donc modifie le pronostic. De tels progrès, en parallèle avec la recherche utilisant des technologies d'imagerie multimodales du cerveau dans les dernières années, comportent des implications prometteuses en clinique malgré les nombreux défis qui ont des incidences sur les soins de santé et l'élaboration de politiques. Cette étude a exploré les perspectives des professionnels Canadiens qui possèdent une expertise, soit dans la recherche en neuroimagerie, dans les troubles de la conscience ou dans ces deux domaines, concernant les applications et les implications cliniques potentielles de la technologie d'imagerie. Méthode: Vingt-deux professionnels de milieux désignés de neuroimagerie, soit des chercheurs, des éthiciens, des avocats et des praticiens ont participé à des entrevues semi-structurées. Les données ont été analysées pour déceler des thèmes émergents. Résultats: Les 5 principaux thèmes émergents étaient les suivants: (1) la validation et la calibration des méthodes; (2) le consentement éclairé; (3) le fardeau pour le système de santé; (4) les implications pour le système de santé canadien; et (5) les possibilités d'améliorer le pronostic. Conclusions: Le transfert de la neuroimagerie des lésions traumatiques cérébrales de la recherche à la clinique requerra qu'on effectue un examen approfondi tant des aspects légaux et éthiques que de la fiabilité de la recherche, de la distribution responsable des ressources en santé et de l'interaction entre les ressources technologiques et les résultats chez les patients.

Keywords: brain injury, neuroethics, neuroimaging, TBI (traumatic brain injury), MCS (minimally conscious state), PVS (permanent vegetative state), ethics, qualitative methods

doi:10.1017/cjn.2015.8

Can J Neurol Sci. 2015; 42: 96-105

Acquired brain injury ( $\mathrm{ABI}$ ), comprising both traumatic brain injury and nontraumatic brain injury such as stroke, anoxia, and infection, is a major cause of death and disability in developed countries. In Canada, more than 40,000 people are hospitalized

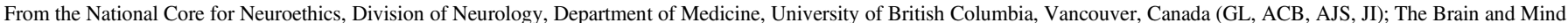

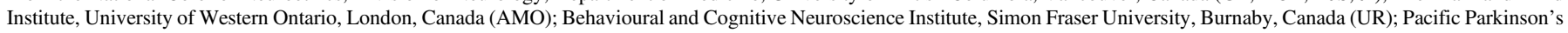

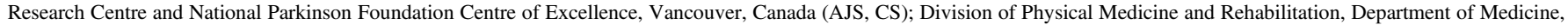

Faculty of Medicine, University of British Columbia, Vancouver, Canada (AT).

Received June 16, 2014. Final Revisions Submitted December 3, 2014.

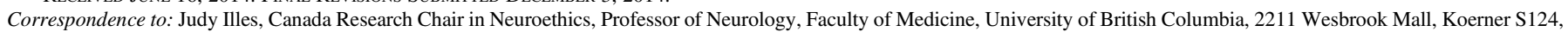
Vancouver, BC, Canada V6T 2B5. Email: jilles@mail.ubc.ca 
with an $\mathrm{ABI}$ each year, and more than $9 \%$ of these patients require posthospitalization rehabilitation. ${ }^{1-3}$ Some of these patients develop disorders of consciousness (DoC), and remain in a minimally conscious state (MCS), permanent vegetative state (PVS), or locked-in state for years after the original injury.

Using functional magnetic resonance imaging, researchers have detected signals of consciousness in some patients in vegetative states ${ }^{4,5}$ who, according to definitions provided by the Multi-Society Task force are typically in the chronic phase of DOC at 3 months after nontraumatic brain damage or 12 months after traumatic brain injury. ${ }^{6}$ In these noninvasive brain imaging studies of the hemodynamic correlates of neural processes, researchers have obtained measures of activation profiles similar to uninjured controls attempting to follow verbal commands. ${ }^{4,5,7}$ These efforts have led to new hope for improving patient prognosis and have opened the possibility of communication through the imagery-based paradigm. ${ }^{5,8,9}$ As an example, the popular press reported that Scott Routley, a patient of coauthor Adrian Owen, communicated about his pain via this visualization technique. For more than a decade, Routley was believed to have been in a persistent vegetative state after suffering a severe brain injury in a car accident in $2000 .^{10}$

The possibility of communication, if only to express preferences, has the potential to be of benefit to the patient and a tangible recognition of his or her personhood. ${ }^{11,12}$ Furthermore, rapid advancements in multimodal brain imaging technologies in recent years have contributed to a better understanding of the underlying local and large-scale brain network connectivity and dynamics in healthy and injured brains. ${ }^{13,14}$ Advanced neuroimaging methods have promising implications to more accurately differentiate between the locked-in state, MCS, and PVS, a differentiation which could be substantially advantageous to these patients and their families given the uncertainty of conventional clinical diagnostic methods. ${ }^{15,16}$

These advances raise the possibility of refining the clinical diagnosis of vegetative states, but they also raise questions about the ethical, social, and legal feasibility of translating these research capabilities into clinical practice. ${ }^{17,18}$ Although evidence of consciousness demonstrated through neuroimaging may improve the accuracy of prognosis, the implications of such findings raise complex questions about withdrawing life-sustaining treatment from brain-injured patients, and further complicate the already elusive definition of consciousness. ${ }^{19-23}$

Patients' families and high-profile court cases such as that of Hassan Rasouli, who has been on a ventilator since 2010 when he developed meningitis and severe brain damage after surgery to remove a tumour, ${ }^{24,25}$ create pressures to use such technologies before they are adequately validated. A prudential ethic is needed, therefore, to set boundaries for neuroimaging in the context of clinical decision-making. ${ }^{26}$ Although advances in clinical studies of DoC patients have improved prognostic knowledge and refined diagnostic classifications, evidence to date does not support routine use of functional imaging assessments for all patients, and clinicians need to be prepared to respond to uninformed requests from families for access. ${ }^{27}$ Fascination with studying impaired consciousness is not new, ${ }^{28}$ but the more recent and widespread interest in neuroimaging for consciousness highlights the vulnerabilities of families to unrealistic expectations and urges ethical guidance for implementing translational research ${ }^{18,29}$ into clinical practice.
To address these challenges, we explored the views of neuroimaging researchers, practicing physicians, ethicists, and law professors with expertise in neuroimaging, DoC, or both, on the actionability of using neuroimaging to detect signals of consciousness in vegetative patients and its ethical, legal, and social consequences within the Canadian health care environment.

\section{Methods}

We used two strategies in series for this qualitative research study. First, we derived a preliminary framework to guide discourse for the Canadian context based on the literature on the subject and the expertise of the contributing authors. Second, on the basis of that framework, we developed the questions for interviews with a range of experts.

All methods involving human subjects were reviewed and approved by the behavioural research ethics board at the University of British Columbia. Written informed consent was obtained from all research participants.

\section{Framework}

The framework was designed to guide: (1) the criteria for evaluating the clinical actionability of detecting signals of consciousness in patients diagnosed as vegetative; and (2) the nature and scope of the ethical, social, and legal consequences of making the capability to detect such signals available in Canadian health care. Using methods consistent with a consensus-seeking dialogue, ${ }^{30}$ the process was interpretive and iterative. The authors met face-to-face for the first deliberative session, and then worked in virtual meetings and by email exchange until consensus was reached on a final working framework. The framework organizes the impacts on clinical translation into areas of impact specific to people and institutions.

\section{Interviews}

\section{Participant recruitment}

The recruitment plan identified potential participants with expertise in DoC from four groups: neuroimaging researchers, practitioners, ethicists, and lawyers from three Canadian academic centres with major programmes of research in neuroimaging. Participants were identified based on a combination of searches on clinical department websites and websites of Canadian neuroimaging research laboratories. Snowball sampling from identified participants increased the overall recruitment pool of eligible participants.

\section{Interview guide}

The interview guide consisted of a preamble about the current state of neuroimaging research in $\mathrm{DoC}$, a few questions about the demographic and professional background of the participant, and three content sections with both discrete and open questions. The guide was piloted and vetted among the author team and refined to incorporate feedback.

The first content section focused on clinical actionability criteria. This section included seven open questions about technical challenges, clinical outcomes, and the ethical, social, and legal issues that would be encountered in the clinical use of the technology. The questions are shown in Box 1.

This section ended with a final yes/no question to which participants answered whether they thought the technology has 
potential to be clinically useful overall. If the answer was positive, the interview continued with questions in the second section; if negative, the interview skipped to the third section.

The second section focused on the impact of the technology. This section included 11 questions that probed for the potential impact of the technology on specific groups and institutions: patients, families, and other caregivers; influencers of health and legal policy; communicators of research to professionals and the public; and health care systems.

The third section probed participants about why they were negative about the actionability of the technology-for example, for reasons of technical limitations, ethical concerns, lack of

\section{Box 1: Questions in the first section of the interview guide}

(1) Describe any technical challenges in detecting signals of consciousness with functional neuroimaging technology.

(2) Do you think this technology could produce a significant change in outcome in terms of patient care, family, or any other aspects?

(3) Would using this technology create ethical concerns? Would these ethical concerns limit its actionability?

(4) Would using this technology create social impacts? Would these social concerns limit its actionability?

(5) Would using this technology create legal concerns? Would these legal concerns limit its actionability?

(6) Would using this technology create economic concerns? Would these economic concerns limit its actionability?

(7) Do you think neuroimaging for disorders of consciousness has the potential to be clinically useful? Timeline for applicability? benefit to patients, and socioeconomic concerns. Another question explored whether or not participants perceived any benefits of continuing neuroimaging research. The questions for the second and third sections are shown in Boxes 2 and 3, respectively.

\section{Data Collection and Analysis}

The interviews were conducted by one of the authors (GL), audio recorded, transcribed, imported into NVivo 10 (QSR International) for data management and qualitative analysis. Participants' names were replaced with alphanumeric codes to protect their confidentiality. Two authors (GL and ACB) independently reviewed transcripts of 7 randomly selected interviews using open coding to identify provisional major themes and subthemes. ${ }^{31,32}$ These major themes and subthemes were used to create a preliminary coding guide, which was then applied to all transcripts in an independent coding process. The same authors conducted several more rounds of independent open coding and reached consensus to expand the coding guide to include primary and secondary level codes. The process was inductive and iterative, and intercoder differences were reconciled by discussion following qualitative methods described by Creswell ${ }^{33}$ and Glaser and Strauss, ${ }^{34}$ as we have applied in the past to interview data for

\section{Box 3: Questions for the third section of the interview guide}

(1) Why not? (To probe why respondents answered negatively to whether they felt neuroimaging for disorders of consciousness has the potential to be clinically useful.)

(2) Do you believe the research will yield any benefits at all?

Box 2: Questions in the second section of the interview guide

(1) What is needed before this technology can be used in the clinic?

(2) Assuming that signals of consciousness could be detected in patients:

(A) Would these signals have an impact on patient autonomy:

(i) in terms of the patient's ability to communicate preferences?

(ii) in terms of the patient's ability to provide informed consent?

(B) Do you think that signals of consciousness detected by functional neuroimaging could lead to a change in patient prognosis?

(3) Would clinical use of the technology change the way families make decisions for the patient?

(4) Do you think the availability of this neuroimaging technology would have an impact on members of the health care team?

(5) Do you think the nature of health care for these patients will change? How?

(6) What criteria would have to be met before the Canadian health care system would broadly adopt this technology?

(7) What are your views on how this research will impact health care policies around access to health care?

(8) What about its impact on laws concerning competence and consent?

(9) Do you think this research will help us gain new scientific knowledge on brain injury and disorders of consciousness?

(10) How do you think this new knowledge should be communicated?

(11) In your opinion, which imaging modalities are likely to be more fruitful for the application at hand?

(12) I would like to revisit the benchmark questions again to see if you have anything to add to those issues. 
studies of brain imaging and health care and parent perspectives on emerging neurotechnologies. $^{35}$

The data were separated from the coded transcripts and reorganized by question to identify patterns and connections among the codes. ${ }^{36}$ Using an interpretive method, the same authors then reintegrated, organized, and reduced the data around central categories and relationships across all transcripts to develop a more refined coding guide. This refined guide was then used to independently code all transcripts, and intercoder differences were reconciled to reach consensus.

Applicable themes and their constituent subthemes were coded only once per transcript per interview question to control for individual biases from participants repeating the same theme multiple times in a long response to an individual question. Each question was coded separately. If a participant returned to a theme in a response to two or more questions, multiple counts would be recorded for that theme.

\section{RESULTS}

\section{Framework}

Figure 1 depicts the analytic framework. The framework identifies criteria for clinical translation: (1) technical feasibility and quantification of brain imaging data; (2) significant change in outcome; and (3) ethical, social, and legal justifications. Then, the framework provides a decision point to assess clinical actionability. A positive response leads to consideration of the ethical, social, and legal impacts across different groups of stakeholders and institutions. A negative response leads to consideration of challenges and benefits of research.

\section{Interviews}

Eleven hours of interview data were collected and analyzed from 22 participants ( 9 women and 13 men). Participants represented the four target groups as follows: neuroimaging researchers $(\mathrm{n}=3)$, practicing physicians $(\mathrm{n}=8$ [3 neurologists, 3 physiatrists, and 2 neurosurgeons]), ethicists $(n=6)$, and law professors $(n=5)$. All participants held advanced degrees: $\mathrm{MD}, \mathrm{PhD}$, or JD. Seven of the eight physicians declared that they had more than six years of experience working with patients with DoC. Participants from other disciplines had five years of experience or less working with patients with DoC.

All participants responded affirmatively to whether neuroimaging technology had the potential to be clinically useful in detecting signals of consciousness in vegetative state patients. However, the affirmation of clinical utility was not unconditional, as shown by the analysis of the emergent themes.

Thirteen themes dominated the analysis of 483 units of data from the interviews. Each of these 13 themes was coded at least 10 times. Themes with higher coding instances were assigned a higher rank; the highest-ranked theme was coded 28 times. Table 1 shows the top-ranked themes, organized into two major categories: actionability $(\mathrm{n}=5)$ and impact $(\mathrm{n}=8)$. The table also shows the fraction of participants who cited each theme at least

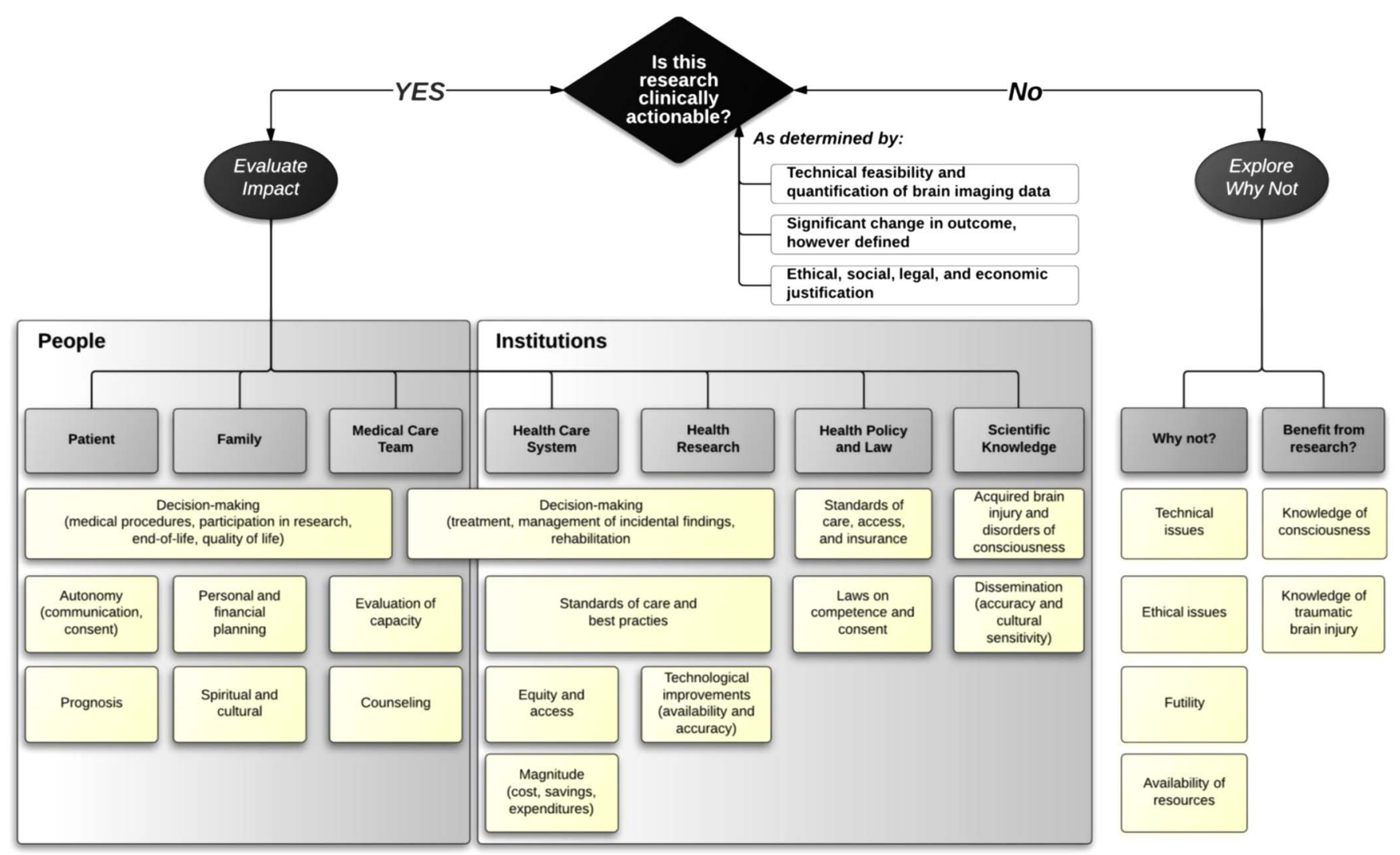

Figure 1: Analytic framework for discerning clinical actionability of neuroimaging for DoC in Canada. The framework identifies seven test nodes: the patient, family, medical care team, health care system, health research, health policy and law, and scientific knowledge. Each node represents an impact variable of neuroimaging evaluated in the context of actionability within the heterogeneity of TBI, patient autonomy, best practices for health care, and human values. 
Table 1: Most frequently coded themes regarding the actionability and impact of neuroimaging technology to detect signals of consciousness in VS patients in Canada

\begin{tabular}{|c|c|c|c|c|c|c|c|}
\hline & & & \multicolumn{5}{|c|}{ Percentage of Participants Referencing Theme at Least Once } \\
\hline & & $\begin{array}{l}\text { Total References } \\
\text { [Rank Overall] }\end{array}$ & $\begin{array}{c}\text { All } \\
{[N=22]}\end{array}$ & $\begin{array}{c}\text { Ethicists } \\
{[N=6]}\end{array}$ & $\begin{array}{c}\text { Lawyers } \\
{[\mathbf{N}=5]}\end{array}$ & $\begin{array}{l}\text { Practitioners } \\
{[\mathbf{N}=8]}\end{array}$ & $\begin{array}{l}\text { Researchers } \\
\quad[\mathbf{N}=3]\end{array}$ \\
\hline \multicolumn{8}{|c|}{ Themes Associated with Actionability } \\
\hline 1 & Validation and calibration of technique & $28[1]$ & $59 \%$ & $33 \%$ & $60 \%$ & $88 \%$ & $33 \%$ \\
\hline 2 & $\begin{array}{l}\text { Uncertainty of a link between signals of consciousness and } \\
\text { changes in prognosis }\end{array}$ & $13[4]$ & $41 \%$ & $67 \%$ & $0 \%$ & $63 \%$ & $0 \%$ \\
\hline 3 & Criteria for appropriate clinical use of this technique & $12[6]$ & $32 \%$ & $50 \%$ & $0 \%$ & $25 \%$ & $67 \%$ \\
\hline 4 & Risks of misinterpretation of signals of consciousness & $11[8]$ & $41 \%$ & $33 \%$ & $0 \%$ & $63 \%$ & $67 \%$ \\
\hline 5 & Skepticism about change in patient's clinical outcome & $11[8]$ & $36 \%$ & $17 \%$ & $0 \%$ & $75 \%$ & $33 \%$ \\
\hline \multicolumn{8}{|c|}{ Themes Associated with Impact } \\
\hline 1 & Difficulty assessing patient capacity to provide informed & $18[2]$ & $50 \%$ & $33 \%$ & $60 \%$ & $38 \%$ & $100 \%$ \\
\hline 2 & Greater burden on health care resources & $15[3]$ & $45 \%$ & $17 \%$ & $60 \%$ & $63 \%$ & $33 \%$ \\
\hline 3 & $\begin{array}{l}\text { Perception the Canadian health care system would never fund } \\
\text { clinical application of this }\end{array}$ & $13[4]$ & $36 \%$ & $17 \%$ & $0 \%$ & $50 \%$ & $100 \%$ \\
\hline 4 & Concerns related to public expectations and understanding & $12[6]$ & $45 \%$ & $0 \%$ & $40 \%$ & $75 \%$ & $67 \%$ \\
\hline 5 & Communication of this work should be via standard scientific & $11[8]$ & $45 \%$ & $17 \%$ & $40 \%$ & $63 \%$ & $67 \%$ \\
\hline 6 & Gives patients a voice and ability to express preferences & $11[8]$ & $27 \%$ & $17 \%$ & $0 \%$ & $25 \%$ & $100 \%$ \\
\hline 7 & Consciousness is not the same as competence & $10[12]$ & $32 \%$ & $17 \%$ & $40 \%$ & $38 \%$ & $33 \%$ \\
\hline 8 & Potential to enhance patient-centered care & $10[12]$ & $23 \%$ & $17 \%$ & $20 \%$ & $38 \%$ & $0 \%$ \\
\hline
\end{tabular}

Rankings were determined by the total number of times each theme was referenced in response to a question over all the interviews. Themes shown here each had more than 10 references. The table also shows the percentage of participants who referenced each theme at least once, with separate columns for all participants and for each of the four participant professions.

once during the interviews. Table 2 shows illustrative quotes representing positive views for actionability. Table 3 shows illustrative quotes for skepticism about the utility of neuroimaging to detect signals of consciousness. Table 4 shows illustrative quotes for overall impact.

\section{Responses Concerning Actionability \\ Validation and calibration of technique}

When considering clinical translation of neuroimaging for unresponsive patients, participants most commonly cited challenges around the translation of methods from the bench to the bedside. Practitioners in particular were concerned about the reproducibility and consistency of the signals detected, not only within a single patient but also across patients with different injuries, different hemodynamics, and different medical histories. Other concerns about validation were more complex, with several participants questioning the precise nature of the phenomena being detected.

"If you say the test is determining that there is the presence of consciousness but that's misleading because you haven't validated it, then you're giving them false hope. Or likewise if

Table 2: Selected participant perspectives on the actionability of detecting signals of consciousness in VS patients in Canada

\section{Themes Associated with Actionability}

1. Validation and calibration of technique

- "... make sure that we have more research in this area and make sure that the technology is as good as possible." (Ethicist ET6)

- "The challenge is that it's not reliable or as trustworthy as just doing brain mapping live, awake surgery... that's really the challenge, is how reproducible is it, how true is it, how accurate is it, because it's really a form of vascular imaging more than it is actual function." (Neurosurgeon PR5)

2. Uncertainty of a link between signals of consciousness and changes in prognosis

- “...the questions that are being asked by the test is what does the test predict. If you could detect consciousness, does that predict that the person will have a meaningful life outcome?" (Neurologist PR8)

3. Criteria for appropriate clinical use of this technique

- “...in the initial deployment of [neuroimaging] technology, the appropriate use isn't always clear. I think that there is a risk that we will overuse it, over apply it in the struggle to understand what best practice is." (Researcher ET4)

4. Risks of misinterpretation of signals of consciousness

- "The interpretation given by somebody can be different than the interpretation given by another person..." (Neurologist PR7)

- "It's not at all clear what [signals of consciousness] mean and as we know the kind of data that we get from [neuroimaging] can be interpreted differently based on the context that someone is looking for." (Ethicist ET2)

5. Skepticism about measurable change in patient's clinical outcome

- "Right now I don't see it doing that in terms of producing a significant change in outcome. It's at best probably more of a tool to see if there is something that's worth pursuing further.." (Physiatrist PR1) 
Table 3: Examples of skepticism on the clinical utility of neuroimaging to detect signals of consciousness in VS patients in Canada

Heterogeneity of disorders of consciousness

- "In a lot of cases the patient's level of consciousness improves over time spontaneously, so there you may not need [neuroimaging] because you can follow them clinically. In the cases where there is a three- to six-month window where they are really in a persistent vegetative state, or at least that's what we think they are, I think that's where the imaging could be really helpful." (Physiatrist PR2)

Insufficient clinical demand

- 'I actually don't see how [neuroimaging] will impact my practice, because the patients are usually—to be honest with you, we withdraw life support before they ever exit the [intensive care unit]... the vast majority of families in those situations, they don't want anything done." (Neurosurgeon PR5)

Insufficiency of research results

- "The other thing that we don't know about using this technology is just because if they show some response on functional [magnetic resonance imaging], does that improve their chances of actually emerging from a lower level of consciousness?" (Physiatrist PR1)

you're saying the test cannot detect any sense of consciousness and it's a hopeless situation but in fact the test missed, wasn't validated, then you could lead to a change in care that could be a poor outcome for the patient." (Neurologist PR8)
"I would say probably again it goes back to the question about what does the result actually represent? Again, you know, there are still questions even among our clinicians in terms of what they may actually represent in terms of the person's awareness or the person's prognosis in the longer term." (Ethicist ET6)

\section{Uncertain link between signals of consciousness and prognosis}

The second highest ranked theme in the category of actionability concerned the correlation of neuroimaging results with patient prognosis, and was cited only by ethicists and practitioners. Participants voiced challenges for neuroimaging in the context of the heterogeneity of consciousness, access to the technique once available for clinical purposes, and the lack of legal guidance to address the problems raised by this technique.

\section{Criteria for appropriate applications}

While reflecting on medical and legal issues involved in the care of patients, participants underscored the need to determine the circumstances under which patients should be referred to neuroimaging, the timing at which such procedures should be administered, and guidelines to guard against overuse and the potential for a drain on the health care economy.

\section{Table 4: Selected participant perspectives on the impact of detecting signals of consciousness in VS patients in Canada}

\section{Themes Associated with Impact}

1. Difficulty obtaining informed consent

- “There's no way of actually testing whether they're competent. We have trouble testing competence in patients who are fully awake and can communicate.... let alone someone who is communicating by [functional magnetic resonance imaging]." (Neurosurgeon PR5)

2. Greater burden on health care resources

- "Other than the actual cost of doing the scans... if somebody thinks that there is something going on based on their functional [magnetic resonance imaging], then the care of this person is prolonged indefinitely. And that care cost can be very high, because most of these people are total care." (Physiatrist PR1)

3. Perception the Canadian health care system would never fund this

- “... [neuroimaging] is still at a place where we're not really sure what it is, how to interpret some of the results... I don't see how we offer it under the healthcare system when we have other services that we're really challenged to provide that we know have direct benefits and have been established. ...it feeds into those larger questions of what constitutes an equitable healthcare system." (Ethicist ET2)

4. Concerns related to public expectations and understanding

- "Signs of consciousness at the very rudimentary level may not be indicative of likelihood of recovery...but families may well latch onto that for reasons of hope." (Ethicist ET2)

5. Communication about this research should be via standard scientific channels

- "It has to be peer reviewed to ensure that it's ethically done research and scientific quality research... then it should be communicated, translated to the public." (Neurologist PR8)

6. Gives patients a voice and ability to express preferences

- "I think [neuroimaging] will help guide us in terms of making sure that they are truly comfortable, ... it can really make a difference in allowing us to understand the patient's preference, and respecting the patient as an individual." (Physiatrist PR2)

- "[Neuroimaging] does help us to see a possibility for otherwise unresponsive patients to exercise a level of autonomy they might not have been before... we have a chance here, perhaps, to enter into at least some form of dialogue." (Researcher ET4)

7. Consciousness is not the same as competence

- “...consciousness is a necessary but not sufficient criterion for giving informed consent, especially if you're going to go on and do something else with that consent." (Law Professor LL1)

- "You would have to go through it the same way that you would ask of any kind of informed consent, whether someone has the capacity to be able to provide the proper informed consent. Just the fact that there is awareness doesn't mean that someone can provide true informed consent." (Researcher RE3)

8. Potential to enhance patient-centered care

- "[Neuroimaging] is going to affect the decisions that capable people make now about their future, and it's certainly going to have broad implications around how we assess best interests, and it has huge financial implications." (Law Professor LL2) 


\begin{abstract}
"I think one of the challenges we have... is that in the initial deployment of technology, the appropriate use isn't always clear. And so I think that there is a risk that we will overuse it, over apply it in the struggle to understand what best practice is. So I think that that does create an economic drain on the health care system." (Ethicist ET4)
\end{abstract}

\section{Risks of misinterpretation}

In light of the heterogeneity of consciousness, participants described the risks of overinterpreting and underinterpreting signals of consciousness measured by neuroimaging. Underinterpretation was described as wrongly assigning a lower level of consciousness to a patient. Overinterpretation was associated with false hope. In describing these conditions, participants predicted that both would create controversy. The lack of baseline data about residual consciousness in vegetative patients was highlighted, as was the obscurity around the meaning of these signals of consciousness.

\begin{abstract}
"Those issues would have to be considered as its being developed for translation, so it'd be the warning box on the use of the technology...when someone is applying the technology, you would have a disclaimer of its limitation, so that whoever is interpreting the measurement would say, 'Well this is how we interpret but there's this margin of error with it,' type approach." (Neurologist PR8)
\end{abstract}

\section{Skepticism about change in outcome}

Other concerns related to skepticism about achieving measurable benefit in the patients' outcome or making a functional change for the patient. In this respect, participants felt that potential changes in signals of consciousness do not necessarily reflect a patient's clinical status. Although participants valued the use of neuroimaging as an adjunct to the clinical examination, they highlighted the lack of correlation between detecting signals of consciousness and being able to improve the patient's condition in a meaningful way.

The reasons that participants gave for expressing skepticism about the clinical utility of neuroimaging to detect signals of consciousness extended beyond measures of patient outcome (Table 3). Participants highlighted the difficulties of finding the appropriate clinical window or context to apply neuroimaging in light of the unpredictably evolving nature of DoCs. They felt that the demand to access neuroimaging would be insufficient to warrant further efforts towards clinical translation because, in today's health care climate at least, families and surrogate decision-makers usually choose to withdraw life-sustaining treatment early. They also expressed concern that the current research findings do not yet make a sufficiently powerful case for clinical translation.

“...you have to prove to me that we can do something with this. We have lots of ways of imaging people's heads and saying this is what's wrong with them, but that's not what I do. What I do is try and make the person so their quality of life is better... We can do a CT of someone's head and show a big bleed, which is fine... But the bottom line is how can we make the person better?" (Neurologist PR8)

\section{Responses Concerning Impact \\ Challenges of informed consent}

The most frequently reported issue concerning impact was related to challenges of informed consent. Respondents highlighted the difficulties of measuring competence even in patients who are awake (Table 4), let alone from brain-injured individuals using functional brain signals as a proxy for speech.

“... you're basically giving someone a treatment for which they can't consent. So, I assume that you're getting the consent of substitute decision makers because you can't get consent from someone until you know whether they have any capacity to consent...So, it's a decision that you're making for an investigative treatment with the substitute decision maker for that person...I would be wary of getting consent for someone for say another medical procedure through this mechanism until we're pretty damn sure that it's really telling us what we think it's telling us." (Law Professional LL1)

\section{Burden on health care resources and lack of government support}

Participants were concerned that clinical availability of neuroimaging would place greater burdens on health care resources because of an increased demand for access to the technology. In parallel, participants predicted that the Canadian health care system would be unwilling to fund clinical applications for neuroimaging even if future research findings demonstrated evidence of a potential benefit to patients. Their concerns stemmed from the difficulty of obtaining funding from already limited health care resources for other diagnostic tools with well-established benefits.

\footnotetext{
"The economic concerns are apparent in the sense in which you must take care of the patient.... You will then have a question as to what to do with a patient who you think has not got much hope of ever experiencing a benefit...more and more patients are put in that category, then more and more bed space must be allocated to them, nursing space, and so forth. So that that will be certainly an extra weight that is put on the allocation of resources and the health care dollars." (Ethicist ET1)
}

\section{Concerns about public misunderstanding and communicating research}

Participants also commented on prerequisites for moving the technique from bench to bedside, including concerns about the expectations and public misunderstanding of neuroimaging, and the need for guidelines specifying appropriate situations in which the technique is indicated. They urged research demonstrating the reliability and reproducibility of neuroimaging to detect signals of consciousness, and suggested translation of peer-reviewed research articles for public communication. 
"I think that the scientific community has an obligation to do their best to help the media convey this information in a coherent and accurate and measured way with clear statements about the limitations of our knowledge and the limitations of the potential, as opposed to, now we can connect with everybody who's in a vegetative state, or whatever the scientific terminology is. I think that the medical community has an obligation to be involved in the dissemination of this information, not just to each other, but to the public as well." (Law Professional LL1)

\section{Potential to give patients a voice and enhance care}

Participants recognized the positive results from assessing residual signs of consciousness in misdiagnosed vegetative patients. These comments touched on the unprecedented ability for patients to voice their preferences, and the accompanying potential of enhancing patient-centered care by taking into account patients' current wishes. Participants saw the potential for signals of consciousness as an avenue through which patients could exercise their autonomy and attending physicians could understand patient preferences that would otherwise be unstated.

"We're trying to give them an interface with their environment. We're trying to get them to be able to communicate their preferences. Do I want to wear a green shirt or a red shirt? Or do I want to watch TV or listen to music? And that kind of autonomy, I think, would be very, very valuable for those kinds of individuals." (Physiatrist PR2)

\section{Dangers of equating consciousness with competence}

Participants felt that demonstration of awareness through neuroimaging is not equivalent to competence. This concern applied specifically to patients' ability to provide informed consent.

\begin{abstract}
“... You can't assume there's competence if there's consciousness...And likewise on consent, informed consent by definition is you have to be able to repeat what was told to you. So, you could be conscious but if you're mute you can't necessarily give informed consent, that's where you have your advocate." (Neurologist PR8)
\end{abstract}

\section{DISCUSSION}

We explored expert opinions on the clinical actionability of neuroimaging to detect signals of consciousness in patients diagnosed as vegetative, and identified the impact this technology would have if translated into clinical practice in Canada. All 22 of the participants in this study agreed that the technology has the potential to be clinically actionable, but not without reservation. Overall, participants' concerns about actionability centered on the need for more translational studies demonstrating reproducible signals, the impact on informed consent, and the challenges around balancing issues of distributive justice and the increasing demands for access to neuroimaging in the face of limited health care resources. They also expressed skepticism about the usefulness of neuroimaging to detect signals of consciousness in DoC patients in the context of the current lack of demonstrable benefits to patients. Participants also recognized a lack of guidance on the appropriate clinical timing and context to prescribe such procedures to patients.

Practitioners (at 36\%) represented the largest subgroup of the participant sample. They spoke most frequently about challenges of ensuring validity and reliability for detecting signals of consciousness in behaviourally unresponsive patients. This complements a recent qualitative study with health care professionals providing clinical care to DoC patients ${ }^{37}$ that showed difficulty and uncertainty in prognostication. Behavioural evidence of awareness of self or the environment upon clinical examination may suggest residual cognitive function in a subset of minimally conscious patients. Neuroimaging studies have contributed to a better understanding of the neurobiological correlates of residual cognition in MCS patients. Differing patterns of functional connectivity $^{38-40}$ and the default mode network ${ }^{41,42}$ have been demonstrated as markers for improving diagnosis and prognosis. Numerous neuroimaging studies of large-scale brain networks in MCS and vegetative state patients have revealed active cortical networks and evidence of language processing, face perception, and sensory functions. ${ }^{43-48}$ However, clinical misdiagnosis between MCS and vegetative state using behavioural criteria continues to be problematic. ${ }^{49,50}$ Resolving the conflict between the practitioners' perceptions and the growing evidence regarding MCS diagnosis and prognosis will be an ongoing challenge to the clinical translation of this technology.

To provide informed consent for medical treatment, a patient must demonstrate decision-making capacity. In considering the impact of clinical translation of neuroimaging research, participants expressed concerns about the circular problem of how behaviourally unresponsive patients could provide informed consent to this procedure. Other commentators have also agreed that providing informed consent is contingent upon the presumption of capacity, which is difficult to assess in DoC patients ${ }^{51-53}$ despite the possibility that they may retain preserved cognition sufficient to meaningfully engage in decision-making. ${ }^{54-56}$

Participants were concerned about the effect this technology would have on the cost of health care. However, analysis of the answers to this question is hampered by a lack of reliable PVS and MCS prevalence rates - not just in Canada but worldwide, ${ }^{57-59}$ and by uncertainty of how detection of signals of consciousness would actually change patient prognosis and treatment and thus affect cost.

Many of the practitioners were cynical about the likelihood of a technology like this being implemented in the Canadian clinical environment, noting that there are advanced imaging and other diagnostic techniques that simply are not funded by the system, even though they have been proven to save money and improve patient outcomes in other countries.

Although many of the participants' responses were cautionary in nature, there was general consensus that this technology has the potential for improving the quality of care for these vulnerable patients, if only by enabling them to express preferences. This potential and the ethical duty it implies is shared by others. ${ }^{60}$

With respect to current research on neuroimaging in patients with DoC, participants were sensible about the need for research ethics guidance for clinical actionability. Participants highlighted the challenges created by public misunderstanding of the limitations of neuroimaging techniques. They reported a range of 
important practical problems related to the interpretation of neuroimaging findings that could create controversy in the broader clinical community, the patient's medical care team, and the patient's family. Given the lack of quality information in the media on brain death, the vegetative and minimally conscious states, and coma, ${ }^{61-64}$ it is unsurprising that public understanding is often discordant with the views of the medical and scientific communities. ${ }^{18,65}$ Although participants did identify standard scientific channels (e.g. peer-reviewed journals, scientific conferences) as the chosen method of research dissemination, science communication, unlike the other issues, did not seem to fall directly under the conventional understanding of ethics challenges. Recent studies addressed public understanding of the science of neuroimaging for DoC by recommending an upstream role for an interdisciplinary panel of experts in communicating research findings to the public. ${ }^{29}$ Complexities in science communication highlight the responsibility that scientific, medical, and key public stakeholders share in addressing public communication and understanding.

\section{Limitations}

Purposive sampling was restricted to participants from three medical centres within Canada. We recognize the limitations of this selection bias. The numbers of participants in each group were small. Most reported that they did not have technical expertise per se, and they had differing levels of knowledge on DoC or neuroimaging. Theoretical saturation was measured across groups rather than for each group; adequacy of the sample size was established when no new concepts emerged from the review of all interviews conducted. ${ }^{34,66}$ The study reveals projections of future applications of technology in the Canadian health care setting, not actual experiences. This latter limitation is generally accepted in qualitative research. ${ }^{30}$

\section{CONCLUSIONS}

This study identified ethical, social, and legal concerns that must be addressed before neuroimaging for signals of consciousness can be a routine part of the clinical care for patients with acquired brain injuries in Canada. It further illuminated the immense knowledge translation task at hand in communicating about advances in modern brain imaging capabilities for DoC.

\section{ACKNOWLEDGEMENTS}

We thank the interview participants for their time and contribution to this study. Support for this research comes from a grant from the Canadian Institutes of Health Research: EOG \#120257 and CNE \#85117.

\section{Disclosures}

GL, ACB, UR, AJS, AT, and CS have nothing to disclose. AMO received research support from Western University Canada Excellence Research Chairs grant, Canadian Institutes of Health Research (CIHR) grant, Canada Foundation for Innovation grant, National Sciences and Engineering Research Council (NSERC) Discovery grant, CIHR Operating grant, McDonnell grant, CIHR Operating grant, and NSERC Research Tools and Instruments grant. JI received support from the Canada Research Chairs Program and CIHR grants EOG \#120257 and CNE \#85117. JI and
AMO both hold grant support on the topic of neuroimaging and disorders of consciousness from the CIHR.

\section{REFERENCES}

1. Chen A, Bushmeneva K, Zagorski B, Colantonio A, Parsons D, Wodchis WP. Direct cost associated with acquired brain injury in Ontario. BMC Neurol. 2012;12:76. Available from: http://www. pubmedcentral.nih.gov/articlerender.fcgi?artid=3518141\&tool= pmcentrez\&rendertype $=$ abstract.

2. Colantonio A, Croxford R, Farooq S, Laporte A, Coyte PC. Trends in hospitalization associated with traumatic brain injury in a publicly insured population, 1992-2002. J Trauma. 2009;66:179-83.

3. Langlois JA, Rutland-Brown W, Wald MM. The epidemiology and impact of traumatic brain injury: abrief overview. J Head Trauma Rehabil. 2006;21:375-8.

4. Owen A, Coleman M, Boly M, Davis M, Laureys S, Pickard JD. Detecting awareness in the vegetative state. Science. 2006;313:1402. Available from: http://www.sciencemag.org/ content/313/5792/1402.short.

5. Monti MM, Vanhaudenhuyse A, Coleman MR, et al. Willful modulation of brain activity in disorders of consciousness. N Engl J Med. 2010;362:579-89.

6. Medical aspects of the persistent vegetative state (2). The MultiSociety Task Force on PVS. N Engl J Med. 1994;330(22):1572-9.

7. Moreno RD, Schiff N, Giacino J, Kalmar K, Hirsch J. A network approach to assessing cognition in disorders of consciousness. Neurology. 2011;75:1871-8.

8. Fernández-Espejo D, Owen AM. Detecting awareness after severe brain injury. Nat Rev Neurosci. 2013;14:801-9.

9. Monti MM, Coleman MR, Owen AM. Neuroimaging and the vegetative state: Resolving the behavioral assessment dilemma? Ann N Y Acad Sci. 2009;1157:81-9.

10. Lunau K. Inside a comatose mind. Macleans. 2013. Available from: http://www.macleans.ca/society/technology/beyond-words/.

11. Wilkinson D, Kahane G, Savulescu J. "Neglected personhood" and neglected questions: remarks on the moral significance of consciousness. Am J Bioeth. 2010;8:31-3.

12. Fins JJ. Border zones of consciousness: another immigration debate? Am J Bioeth. 2007;7:51-4; discussion W1-4.

13. Ribary U. Dynamics of thalamo-cortical network oscillations and human perception. Prog Brain Res. 2005;150:127-42.

14. Ribary U, Doesburg S, Ward L. Thalamocortical network dynamics: a framework for typical/atypical cortical oscillations and connectivity. In: Supek S, Aine AJ, editors. Magnetoencephalography - from signals to dynamic cortical networks. Heidelberg: Springer Verlag; 2014, p. 429-50.

15. Monti MM, Coleman MR, Owen AM. Executive functions in the absence of behavior: functional imaging of the minimally conscious state. Prog Brain Res. 2009;177:249-60.

16. Coleman MR, Bekinschtein T, Monti MM, Owen A, Pickard JD. A multimodal approach to the assessment of patients with disorders of consciousness. Progr Brain Res. 2009;177:231-48.

17. Illes J, De Vries R, Cho MK, Schraedley-Desmond P. ELSI priorities for brain imaging. Am J Bioeth. 2006;6:W24-31.

18. Racine E, Bell E. Clinical and public translation of neuroimaging research in disorders of consciousness challenges current diagnostic and public understanding paradigms. Am J Bioeth. 2008;8:13-5.

19. Wilkinson DJ, Kahane G, Horne M, Savulescu J. Functional neuroimaging and withdrawal of life-sustaining treatment from vegetative patients. J Med Ethics. 2009;35:508-11.

20. Kahane G, Savulescu J. Brain damage and the moral significance of consciousness. J Med Philos. 2009;34:6-26.

21. Fins J. Neuroethics, neuroimaging, and disorders of consciousness: promise or peril? Trans Am Clin Climatol Assoc. 2010;122: 336-346.

22. Lanoix M. Where angels fear to tread: proxy consent and novel technologies. Brain Inj. 2010;24:1336-42.

23. Tovino S, Winslade W. A primer on the law and ethics of treatment, research, and public policy in the context of severe traumatic brain injury. Ann Heal Law. 2005;14:1-52. 
24. Cooper AB, Chidwick P, Sibbald R. Court rules that withdrawal of life support is a plan of treatment requiring consent. Can Med Assoc J. 2011;183:E467.

25. Dyer O. Doctors fail to get life support withdrawn from "minimally conscious" patient. BMJ Br Med J. 2013;347:f6366.

26. Lee G, Illes J. Never say never: limitations of neuroimaging for communicating decisions after brain injury. AJOB Neurosci. $2013 ; 4: 3-4$

27. Jox RJ, Bernat JL, Laureys S, Racine E. Disorders of consciousness: responding to requests for novel diagnostic and therapeutic interventions. Lancet Neurol. 2012;11:732-8.

28. Koehler PJ, Wijdicks EFM. Historical study of coma: looking back through medical and neurological texts. Brain. 2008;131: 877-889.

29. Fins JJ, Illes J, Bernat JL, Hirsch J, Laureys S, Murphy E. Neuroimaging and disorders of consciousness: envisioning an ethical research agenda. Am J Bioeth Ajob. 2008;8:3-12.

30. Kvale S. Dominance through interviews and dialogues. Qual Inq. 2006;12:480-500.

31. Boeije H. A purposeful approach to the constant comparative method in the analysis of qualitative interviews. Qual Quant. 2002;36: 391-409.

32. Creswell J. Qualitative inquiry and research design. 3rd ed. Thousand Oaks, CA: SAGE Publications; 2013. p. 472.

33. Creswell JW. Research design: qualitative, quantitative, and mixed methods approaches. 2nd ed. Thousand Oaks, CA: SAGE Publications; 2003.

34. Glaser B, Strauss A. The discovery of grounded theory: strategies for qualitative research. Chicago: Aldine; 1967.

35. Borgelt EL, Buchman DZ, Weiss M, Illes J. In search of "anything that would help": parent perspectives on emerging neurotechnologies. J Atten Disord. 2012;18:395-401.

36. Miles MB, Huberman AM, Saldana J. Qualitative data analysis: a methods sourcebook. 2nd ed. Thousand Oaks, CA: SAGE Publications; 1994.

37. Rodrigue C, Riopelle RJ, Bernat JL, Racine E. Perspectives and experience of healthcare professionals on diagnosis, prognosis, and end-of-life decision making in patients with disorders of consciousness. Neuroethics. 2013;6:25-36.

38. Laureys S, Owen A, Schiff N. Brain function in coma, vegetative state, and related disorders. Lancet Neurol. 2004;3:537-46.

39. Boly M, Massimini M, Tononi G. Theoretical approaches to the diagnosis of altered states of consciousness. Prog Brain Res. 2009; 177:383-98.

40. Cauda F, Micon BM, Sacco K, et al. Disrupted intrinsic functional connectivity in the vegetative state. J Neurol Neurosurg Psychiatry. 2009;80(4):429-31.

41. Fernández-Espejo D, Soddu A, Cruse D, et al. A role for the default mode network in the bases of disorders of consciousness. Ann Neurol. 2012;72:335-43.

42. Vanhaudenhuyse A, Noirhomme Q, Tshibanda LJ-F, et al. Default network connectivity reflects the level of consciousness in noncommunicative brain-damaged patients. Brain. 2010;133:161-71.

43. Schiff ND, Ribary U, Moreno DR, et al. Residual cerebral activity and behavioural fragments can remain in the persistently vegetative brain. Brain. 2002;125(Pt 6):1210-34.

44. Laureys S, Faymonville ME, Peigneux $\mathrm{P}$, et al. Cortical processing of noxious somatosensory stimuli in the persistent vegetative state. Neuroimage. 2002;17:732-41.

45. Boly M, Faymonville M-E, Peigneux P, et al. Auditory processing in severely brain injured patients. Arch Neurol. 2004;61:233-8.
46. Laureys S, Perrin F, Faymonville M, et al. Cerebral processing in the minimally conscious state. Neurology. 2004;63:916-8.

47. Coleman MR, Rodd JM, Davis MH, et al. Do vegetative patients retain aspects of language comprehension? Evidence from fMRI. Brain. 2007;130:2494-507.

48. Boly M, Faymonville ME, Schnakers C, et al. Perception of pain in the minimally conscious state with PET activation: an observational study. Lancet Neurol. 2008;7:1013-20.

49. Andrews K, Murphy L, Munday R, Littlewood C. Misdiagnosis of the vegetative state: retrospective study in a rehabilitation unit. BMJ. 1996;313:13-6.

50. Childs N, Mercer W, Childs H. Accuracy of diagnosis of persistent vegetative state. Neurology. 1993;43:1465-7.

51. Appelbaum P, Grisso T. The MacArthur Treatment Competence Study. I: mental illness and competence to consent to treatment. Law Hum Behav. 1995;19:105-26.

52. Karlawish J. Measuring decision-making capacity in cognitively impaired individuals. NeuroSignals. 2008;16:91-8.

53. Appelbaum PS. Consent in impaired populations. Curr Neurol Neurosci Rep. 2010;10:367-73.

54. Peterson A, Naci L, Weijer C, et al. Assessing decision making capacity in the behaviorally non-responsive patient with residual covert awareness. AJOB Neurosci. 2013;4:3-14.

55. Peterson A, Naci L, Weijer C, Owen AM. A principled argument, but not a practical one. AJOB Neurosci. 2013;4:52-3.

56. Bach M, Kerzner L. A new paradigm for protecting autonomy and the right to legal capacity. Prepared for the Law Commission of Ontario. 2010. Available from: http://www.lco-cdo.org/disabilities/ bach-kerzner.pdf.

57. Pisa FE, Biasutti E, Drigo D, Barbone F. The prevalence of vegetative and minimally conscious states: a systematic review and methodological appraisal. J Head Trauma Rehabil. 2014;29:E23-30.

58. Craemer R. Funding arrangements for diagnostic imaging services: an international literature review. Prepared for the Department of Health and Ageing. 2010. Available from: http://www.thescannermagazine.com/images/pdfs/pdf16.pdf.

59. Fins J. Brain injury: the vegetative and minimally conscious states. In: Crowley M, editor. From Birth to Death Bench to Clinic. The Hastings Center. Bioethics Briefing Book for Journalists, Policymakers, and Campaigns. Garrison, NY: The Hastings Center; 2008. p. 15-20; Available from: http://childpsychaitry. thehastingscenter.org/uploadedFiles/Publications/Briefing_Book/ braininjurychapter.pdf.

60. Fins J. Constructing an ethical stereotaxy for severe brain injury: balancing risks, benefits and access. Nat Rev Neurosci. 2003; 4:3-7.

61. Wijdicks EFM, Wijdicks MF. Coverage of coma in headlines of US newspapers from 2001 through 2005. Mayo Clin Proc. 2006; 81:1332-6.

62. Racine E, Bar-Ilan O, Illes J. fMRI in the public eye. Nat Rev Neurosci. 2005;6:159-64.

63. Racine E, Bar-Ilan O, Illes J. Brain imaging: a decade of coverage in the print media. Sci Commun. 2006;28:122-42.

64. Samuel G, Kitzinger J. Reporting consciousness in coma: media framing of neuro-scientific research, hope, and the response of families with relatives in vegetative and minimally conscious states. JOMEC J. 2013;3:1-15.

65. Wardlaw JM, O'Connell G, Shuler K, et al. "Can it read my mind?" What do the public and experts think of the current (mis)uses of neuroimaging? PLoS One. 2011;6:e25829.

66. Morse JM. The significance of saturation. Qual Health Res. 1995; $5: 147-9$ 